\title{
A CLOSER LOOK INTO AN ESP COURSE THROUGH STUDENTS' END-OF-COURSE EVALUATIONS: A CASE STUDY
}

\author{
Handan Çelik \\ Trakya University, Edirne, Turkey \\ E-Mail: handancelik@trakya.edu.tr
}

\begin{abstract}
With no doubt, evaluation has a significant role to ensure continuous improvement of any course, and ESP course, which is included in language teaching programs to satisfy a particular need, is not an exception. However, ESP course evaluation studies are still rare. With this in mind, this study reports the tertiary level students' end-of-course evaluations regarding the ESP course offered within Banking department at Applied Sciences School of a state university in Turkey. Adopting survey methodology to unearth instances of the case being examined within its natural context from the perspective of its participants i.e. the students, the study gathered quantitative data through a scale which the students $(N=96)$ reflected back on; the ESP practitioner, course materials, and course, and also qualitative data via open-ended items to elicit the students' evaluations regarding the strengths of the course and likely changes and improvements. While the analysis of the quantitative data broadly showed the students' satisfaction with the ESP practitioner, course materials, and the course itself, the content analysis of the qualitative data revealed insights regarding such issues as content-specific instruction and language skills development as strengths of the course. However, the qualitative data also showed that the students' evaluations upon likely changes and improvements such as use of L1, teacher talk, and assessment diverged, which indicate heterogeneity as a challenge along the way impeding the effectiveness of ESP courses.
\end{abstract}

Key words: course evaluation, ESP practitioners, language skills, strengths, weaknesses

\section{INTRODUCTION}

Due to the changes and demands in knowledge and technology societies, education, particularly language education, has also been through changes. Thus, as suggested by Lesiak-Bielawska (2014), 20 ${ }^{\text {th }}$ century changed the foreign language classrooms, and ESP, which "refers to the teaching and learning of English as a second or foreign language and in which the goal of learners is to use English in a particular domain" (Paltridge and Starfield 2013 , p. 2), gradually became a multilayered language teaching approach basing its curricula and content on needs or profession of learners mostly having diverse educational and professional background. Besides, in most countries, where English is taught as a foreign language, the number of institutions offering instruction through English increases, thus, interest goes beyond teaching and researching language within new and diverse academic contexts (Paltridge and Starfield 2013).

In this regard, ESP, as an approach to language teaching through "sets of transferable generic language and literacy skills that are seen to be applicable in the majority of academic and workplace setting" (Paltridge and Starfield 2013, p.31), is concerned with 
designing appropriate courses which are based on learner needs analysis, and followed by substantial processes of syllabus design; materials design, selection, and evaluation; classroom teaching; and also evaluation proceeding in a linear fashion (Hutchinson and Waters 1987; Paltridge and Starfield 2013). As seen, evaluation, which in its very basic sense refers to inquiring something and eliciting answers, making judgements, replanning and reacting accordingly (Dudley-Evans and St John 1998; Lynch 1996), is one of the key components of ESP teaching. However, evaluation is an inherently complicated and multifaceted process requiring a nuanced understanding of what and how to evaluate, means to collect and analyze information to evaluate, and also means to act and react to enhance what is being evaluated (Morgan 2008).

With this in mind, the current study set out to explore the tertiary level students' endof-course evaluations regarding if and how the ESP course that they were offered in Banking department did well. As the students were important source of information, to get a complete sense of their evaluations regarding the effectiveness of the course, they were asked to evaluate; the ESP practitioner mainly from a pedagogical perspective, the materials if and to what extent they matched the course and fulfilled their needs, and the course particularly for technical details. The students were also prompted with openended questions to further elicit their thoughts regarding the strengths of the course and likely changes and improvements.

\section{EVALUATION IN ESP COURSES}

Within ESP situations, evaluation is concerned with the effectiveness and efficiency of learning regarding if the objectives defined through needs analysis (if there is any) have been met, if learners' learning has been maximized, or if resources have been employed to the fullest and their best, and also if the methodology adopted by the ESP practitioner has matched learners' needs, and thus has facilitated their learning and achievements (DudleyEvans and St John 1998; Hutchinson and Waters 1987). Besides, like any other course, ESP course needs to show and justify "its continued existence in its present form" (Hutchinson and Waters 1987, p. 152). Similarly, ESP course evaluation is almost a must to achieve a richer understanding regarding if and how what students engage in throughout the ESP process affect and facilitate their learning ( $\mathrm{Su}$ 2009). As might clearly be inferred, evaluation, which needs to be built in as part of course design as suggested by DudleyEvans and St John (1998), is a very comprehensive action towards getting a clear and complete sense of if and how the course actually fulfills its function.

With this in mind, anything and everything that can be of significance can be evaluated through such means as learners' test results, questionnaires, discussions, interviews, or even informal chats. However, it is not only learners, but also any party closely concerned with the ESP teaching can be involved in the evaluation. For this reason, the institution that the ESP course is being offered, ESP practitioners, former students, and even sponsors (if there are any) can take part in evaluation as its vital to get a cross-section of views (Hutchinson and Waters 1987). However, Hutchinson and Waters further add that with learners, in particular, it can be difficult to get feedback, which is an expression of their real views, as they may hesitate to criticize the authority, which is generally the teacher, since they possibly think it might prejudice their assessment or they might simply consider the evaluation will do no benefit to them rather to the future learners. However, despite such challenges along the way, getting learners' 
evaluations, as the very insiders to the course, is vital to provide deeper insight for learning experiences and processes that can further be accommodated. Last but not the least, when and how often evaluation should take place is another matter of concern, and the most important times to evaluate an ESP course are suggested as; the very first week of the course if the initial impressions are aimed to be gathered, at regular intervals as indicators of sensitive and responsive teaching, end-of-course evaluations, or after-course evaluations which are suggested to be the most valuable ones as learners are now in a position to judge if and how the course fulfilled their learning needs and equipped them with the knowledge and skills they need (Dudley-Evans and St John 1998; Hutchinson and Waters 1987).

As an evidence of the demand for effective ESP courses, over the last decades, effectiveness and efficiency of ESP courses at tertiary level have gained importance (Chostelidou 2011). Despite their significance, there has been limited research (see Aliakbari and Boghayeri 2014; Dhieb-Henia 2003; Hatam and Shafiei 2012; Pasalic 2013; PapadimaSophocleous and Hadjiconstantinou 2013; Pranckeviciute and Zajankauskaite 2012; Tsou and Chen 2014; Zoghipour 2017). For instance in their study Hatam and Shafiei (2012) examined the effectiveness of an ESP course offered to engineering students regarding if it improved their skills to translate job-related texts from English to Persian. In another study, Aliakbari and Boghayeri (2014) investigated needs and views of architecture students and graduates for the effectiveness of their ESP courses with regard to such particular issues as language skills, coursebook, topics, and length of the course, and revealed that the course did not meet the learners' needs, thus necessitated revisions. Pranckeviciute and Zajankauskaite, (2012) dealt with roles of needs analysis and materials evaluation in adjusting ESP courses to the learners' needs. In their comprehensive ESP program evaluation, Tsou and Chen (2014) dealt also with course evaluation and sought for if learners' needs were fulfilled, if tasks and materials were authentic, and if the course was successful to foster learner autonomy. In her study DhiebHenia (2003) also evaluated the ESP course with regard to its effectiveness in metacognitive strategy training on a group of undergraduate students' declarative and procedural knowledge and their choice and use of strategy while reading research articles. Moreover, Zoghipour (2017) examined the strengths and weaknesses of the courses offered to engineering students.

Similarly, the scarcity of research in Turkish context is clearly evident. There have only been few studies examining ESP courses at tertiary level from students' perspectives (see Demirbulak 1992; İlin, Kutlu, and Kutluay 2013). In her study on learners' perceptions of effectiveness of ESP courses offered at tertiary education, Demirbudak (1992) elicited former students' evaluations as they were thought to be in the target situation for which they had been prepared for, thus could reflect better if the course met their needs. Besides, ESP course is also seen to serve as a context to test how a particular technique, videos, on explicit grammar teaching worked (see İlin et al. 2013). As can be seen, both globally and locally, the scarcity of ESP course evaluation research is visible, and encourages researchers more for more studies. As one of those attempts, details regarding the methodological issues are presented in the following sub-sections.

\section{METHODOLOGY AND InSTRUMENTATION}

So as to answer the aforementioned concerns, and to conduct "in-depth study of instances of a phenomenon in its natural context and from the perspective of participants involved in the phenomenon" (Gall et al. 2003, cited in Duff 2008, p. 22), the survey methodology, as a convenient means to get a snapshot of the condition from a large sample 
at a single point in time (see Dörnyei 2007; Nunan and Bailey 2009), was adopted through a 5-point Likert scale and open-ended items.

The scale, ranging from highly satisfactory to highly unsatisfactory, included 28 -items within three domains namely; the ESP practitioner, the materials, and the course. For instance, as for the ESP practitioner, the focus was on the pedagogical issues such as subject-matter knowledge, use of appropriate teaching methodology, communicating effectively with the students, taking care of the students' learning, or relating the content with each other (appropriate transitions between the content). The items for the materials were to see if the materials matched the learners' level and the content, if they were contributory on students' learning (educational strength and value), and also if they were appropriate for and served for the development of the students' language skills, i.e. reading, writing, listening, speaking, grammar, vocabulary, and pronunciation. As for the course, the adequacy of class hours and appropriateness and effectiveness of the classroom (physical size) were evaluated. Besides, to let the students have some form of flexibility to express their thoughts and evaluations, which were not targeted through the scale, or accidentally dismissed, three open-ended questions were included. This was also to elicit further information upon the strengths and weaknesses of the course. In other words, as Nunan and Bailey (2009) stated, it was to "allow respondent to express mixed feelings and shades of meaning" (p. 137). Thus, the questions were to see; the strengths of the course, what they would change if they would like to change anything regarding the flow of the course, and likely improvements regarding such issues as exams, homework particularly for their appropriateness and density.

Additionally, validation of the instrument was of critical importance to assure that it could elicit what was aimed. Thus, to eliminate likely problems which could result from wording or clarity of items and questioning, the researcher asked for the help of another colleague tutoring the EAP courses in the school. Thus, the closed and open items were reviewed for clarity, wording, and appropriateness and strength in capturing the students' evaluations. Through the negotiations with the colleague, the instrument was fine-tuned. Besides, a student who was taking the course was asked to respond to the instrument, and provide feedback if the items and questions were clear. Therefore, through this mini-piloting, the researcher tried to establish if the instrument could work as it was supposed to work.

\subsection{Evaluand and participants}

The course, which is under evaluation, is offered in the Banking department within the Applied Sciences School, and it was preceded by two EAP courses offered through the $1^{\text {st }}$ and $2^{\text {nd }}$ years in the program, and followed by another ESP course in the $4^{\text {th }}$ year. The course, targeting the delayed needs, was compulsory, assessed, and extensive (see Dudley-Evans and St John 1998) running alongside the other courses in the department program. It was a weekly 4-hour course covering both fall and spring terms, which made approximately 28 weeks in total, excluding the winter break, and had 112 hours (more or less) of classroom instruction. As there was no administrational, pre-determined set of aims and objectives for the course, the teacher, whoever tutored the course, was given some sort of freedom to determine and design his or her own course content. However, this, unfortunately, meant that there was no administrational support and guidance regarding their expectations from the course, and it left a gap for what to be covered and achieved through the course. In this sense, the teacher was most probably seen as source of knowledge rather than a facilitator of the content defined by the students' needs and 
supported by the departmental subject matter experts. Therefore, there was nothing in hand regarding if the focus of the course was expected to be narrow, i.e. a specific skill like reading or broad, in other words a variety of skills (see Dudley-Evans and St John 1998). Besides, there was no requirement and guidance regarding the materials to be used. The course was taken by the students in day and night groups in the department. This also meant that the groups, approximately having 200 students changing between 20 and 26 (21 on average), including the retakes, were naturally heterogeneous. As known, such groups include learners with various needs, interests, background knowledge and skills, and ultimately with diverse language level. Therefore, they would ultimately have different motivations and concerns, and this could potentially make the course tutor's job harder.

In such a case, the researcher, who was tutoring the course, designed an integrated-skills, receptive and productive skills, complemented by vocabulary, grammar, and pronunciation, course which aimed to help the students acquire and develop content-specific skills and knowledge. However, as known, for English teachers tutoring ESP courses, selection and designing of appropriate content is an area of great difficulty as they lack knowledge of that specific subject (see Strevens 1988). Therefore, the basic step for such a course was to begin with selection of a strong coursebook which the researcher thought would be of great help and guidance to her for a well-grounded course. Thus, after examination of alternatives for Banking students, the coursebook Finance by Oxford University Press was selected as a guide to be complemented by some other materials such as relevant newspaper articles and news videos which would facilitate effective teaching and learning of all skills. For instance, as for reading skills, which included such texts as stock markets, financing the company, or outsourcing financial services, the researcher included main skills i.e. skimming, scanning, and cloze reading which were to support the students' knowledge and skills' development regarding identifying main ideas by reading the titles, finding specific information in the texts, or distinguishing main points from supporting ideas. For vocabulary skills, the content covered exercises to enable the students to learn and practice word structure and to distinguish between different sorts of words in different contexts such as banks and their products or industries and sectors. Besides, responding to customer complaints, writing a reminder for non-payments, or reporting on insurance claims were some of the writing tasks. The videos which came from the news at that time were used to encourage the development of the students' speaking skills such as negotiation of the main ideas, agreeing or disagreeing with the ideas in the material, or conveying meaning appropriately in a given situation. However, this, surely, could not guarantee that what she did would work, be a hundred percent effective, and fulfill the students' needs and expectations.

Putting all these together, the challenge running behind designing and tutoring an effective ESP course was clearly evident, and this encouraged the researcher to take the control of the job she did, and if what she did really worked. As a result, it was a motivation for the researcher to report what she gained through the analysis regarding the students' evaluations of the effectiveness of the course.

\subsection{Data collection and analysis}

Thus, to collect data, the researcher administered the instrument at the end of the course whereby the students were about to leave the whole process behind, and presumably achieved a more sound and valid account of the course process. Besides, as Hutchinson and Waters (1987) stated, it was difficult to decide when to evaluate the course as the students would probably avoid sharing their thoughts openly as they could assume it a kind of 
disrespect to the teacher. Therefore, end-of-course evaluation was the most appropriate means to conduct the evaluation. For this reason, on the day when the students gathered for their final exam, the instrument was group administered (see Dörnyei 2009). The students were informed about the purpose and significance of the instrument before they were given it. They were also assured that it had no link to their classroom performance or final evaluation, but rather to see how the course was effective to fulfill their needs and support their learning and achievements. They were also clarified that they had the right to not to respond. After the elimination of those which were responded only as highly satisfactory or highly unsatisfactory as they seemed to be paid no critical consideration, 96 carefully responded instruments left. Within them, a great majority $(n=80)$ also included responses to the open-ended questions.

For quantitative analysis, descriptive means were calculated, while the analysis of the qualitative data was conducted through content analysis which is "exploratory in process, and predictive or inferential in intent" (Krippendorff 2004, p.xvii). Results gained through both types of analyses are presented in the following section.

\section{FINDINGS}

To make a thorough sense of the students' evaluations of the ESP course, both quantitative and qualitative data are presented in this section. For the interpretation of the quantitative data, items with means with and above 4.00 were considered as highly satisfactory, while those between 3.99 and 3.00 were considered as satisfactory. First and foremost, the findings gathered through the scale regarding the ESP practitioner, the materials, and the course are presented (see Table 1).

Table 1 The students' evaluations regarding the ESP practitioner $(N=96)$

\begin{tabular}{lcr}
\hline The ESP practitioner; & M & SD \\
\hline Being prepared for the classes & 4.29 & .68 \\
Subject-matter knowledge & 4.28 & .69 \\
Providing effective explanations to the students' questions & 4.08 & .92 \\
Taking care of the students' learning & 4.04 & 1.07 \\
Effective use of course materials & 4.02 & .96 \\
Making effective transitions between the content & 3.96 & .73 \\
Linking the content with each other & 3.90 & .91 \\
Effective communication with the students & 3.85 & 1.05 \\
Use of appropriate teaching methodology & 3.69 & 1.09 \\
Taking the students' attention to what is being studied & 3.43 & 1.06 \\
\hline
\end{tabular}

As the table shows, the students' evaluations regarding the ESP practitioner were tried to be captured from different perspectives such as knowledge and skills, manner, and rapport with the students. The issues that the students found as highly satisfactory were the practitioner's preparedness for the classes $(M=4.29)$, which was followed very closely by her subject-matter knowledge $(M=4.28)$. Providing effective explanations to the students' questions $(M=4.08)$ and taking care of their learning $(M=4.04)$, which are actually complementary, were found to be some other issues that the students regarded as highly satisfactory. The practitioner's use of course materials effectively $(M=4.02)$ was also seen as 
highly satisfactory, and followed by making effective transitions between the content $(M=3.96)$, and linking the content with each other $(M=3.90)$ as satisfactory issues. The practitioner's communication with the students was also found to be satisfactorily effective $(M=3.85)$. Surprisingly, the practitioner's use of appropriate teaching methodology $(M=3.69)$ and taking the students' attention to what is being studied $(M=3.43)$ were thought to be satisfactory likely results of which are hidden in the students' responses to the open-ended items. Last but not the least, standard deviation (SD) value of some items, such as the last three, are relatively higher, and this indicates the variation and separation among the students upon some issues suggesting that while some found it satisfactory, others did unsatisfactory. This, surely associated with the group's heterogeneity.

Besides, the students were also asked to evaluate the course materials (see Table 2).

Table 2 The students' evaluations regarding the course materials $(\mathrm{N}=96)$

\begin{tabular}{lcc}
\hline The course materials; & M & SD \\
\hline Appropriateness of the coursebook & 3.76 & .83 \\
Quality (educational value and strength) & 3.66 & .99 \\
Compatibility of the content with job-related knowledge and skills & 3.62 & 1.16 \\
Appropriateness to the students' level & 3.43 & 1.01 \\
Adequacy of the technical equipment & 3.33 & 1.09 \\
Appropriateness for; & & \\
- Reading skills & 3.82 & .82 \\
- Listening skills & 3.77 & .89 \\
- Grammar & 3.76 & .98 \\
- Writing skills & 3.75 & .86 \\
- Vocabulary skills & 3.72 & .90 \\
- Speaking skills & 3.62 & .92 \\
- Pronunciation & 3.55 & 1.09 \\
\hline
\end{tabular}

As seen, in a general sense, the students regarded the course materials as satisfactory. The coursebook was thought as more satisfactory $(M=3.76)$ possibly because it was the main the source of the content complemented by news articles and videos. They regarded the materials as qualified which meant that they are of educational value and strength $(M=3.66)$ as they also found them compatible with the job-related knowledge and skills $(M=3.62)$. On the other hand, they perceived them relatively less satisfactory with regard to appropriateness to their level $(M=3.43)$. Technical equipment i.e. computer, internet facility, tape-recorder, CDs, and speakers, were also seen as less satisfactory $(M=3.33)$, and this definitely makes sense as there was no further support from the administration regarding the quality and effectiveness of the equipment available. The students' evaluations upon the appropriateness of the materials for the development of language skills were also elicited, and they were seen to find them satisfactory in a general sense. For instance, they regarded the reading skills materials relatively more satisfactory $(M=3.82)$ when compared to listening $(M=377)$, grammar $(M=3.76)$, writing $(M=3.75)$, and vocabulary $(M=3.72)$ which are very close though. Speaking $(M=3.62)$ and pronunciation $(M=3.55)$ skills materials were found to be less satisfactory for the development of the related language skills.

Another issue was how the students evaluated the course, particularly for technical details such as the class hours, appropriateness of its pace, or even the physical size of the classroom (see Table 3). 
Table 3 The students' evaluations regarding the course $(\mathrm{N}=96)$

\begin{tabular}{lcc}
\hline The course; & M & SD \\
\hline Adequacy of class hours & 3.75 & 1.16 \\
Appropriateness of the course pace & 3.58 & 1.08 \\
Adequacy of the classroom (physical size) & 3.51 & 1.12 \\
Adequacy of pair work & 3.47 & 1.11 \\
Adequacy of group work & 3.46 & 1.08 \\
Adequacy of individual work & 3.41 & 1.19 \\
\hline
\end{tabular}

As shown, the students regarded the class hours $(M=3.75)$ and its pace $(M=3.58)$ as satisfactory. However, the level of their satisfaction seems to decrease when it comes to the physical size of the classroom $(M=3.51)$. As it is mentioned before, the group size was unfortunately big, and the number of regular students in both day and night groups changed between 45 and 60 . Thus, it made it hard, as it would surely not be same as a small size group. Quite complementarily, due to the group size, pair, group, and individual work practices, changing between 3.41 and 3.47, was found to be relatively less satisfactory. As might be understood, in big groups, it naturally becomes a challenge for practitioners to season their practices with adequately and effectively planned and conducted practices. Also, SD values of all items deserve attention as they are bigger than 1.00 which suggests the divergence within the students concerning the issues under examination.

The evaluations elicited through the open-ended items are also seen to complement the quantitative findings, and unearth the likely reasons behind their evaluations provided above. First and foremost, the students' responses to the first question asking for the most contributory aspects, in other words strengths, of the course are tabulated (see Table 4).

Table 4 Strengths of the course $(n=80)$

\begin{tabular}{lr}
\hline Themes & $\mathrm{f}$ \\
\hline Language skills development & \\
- Vocabulary & 20 \\
- Listening & 5 \\
- Ppeaking & 4 \\
- Writing & 4 \\
- Grammar & 4 \\
English as medium of instruction & 3 \\
Content-specific instruction & 20 \\
Group work & 14 \\
Web quests & 4 \\
Coursebook & 2 \\
Revisions & 2 \\
Homework & 2 \\
Total & 2 \\
\hline
\end{tabular}

As seen, the contribution which they benefitted the most was the course's effectiveness in supporting the development of language skills ranging from vocabulary to grammar $(f=40$ in total). The skill which the students thought to develop most was vocabulary $(f=20)$. 
They regarded active use of English as medium of instruction $(f=20)$ as another strength of the classes. This might initially sound as weird as it is an English course; however, unfortunately in Turkish context native language (L1) is known to be used commonly in language classrooms, and a great of majority of teachers from primary to university level are known to use Turkish, more or less, as medium of instruction in English classes. For this reason, the ESP practitioner's active use of English was frequently mentioned as a contribution as it also meant that the students were exposed to target language input which is key for language skills development. For instance, S13 stated that "the teacher's use of English positively affected me, and even my ability to think in English developed". For another one, "active use of English in the class acted as a facilitator on my development, and I can even say that this was the teacher's most efficient characteristic compared to my previous teachers" (S16). Besides, content-specific instruction $(f=14)$ was also seen as another strength. "As the course is related to our field (content), it builds the basis for financial language without a need for further language courses. Also, I think that what we learn in the course will help us get prepared and take the field exams" S46. The students further mentioned some other issues like group work $(f=4)$, web quests $(f=2)$, coursebook $(f=2)$, revisions $(f=2)$, and homework $(f=2)$ as the strengths of the course.

Besides, the students were asked what they would change if they wanted to do so, and their responses showed various issues (see table 5).

Table 5 Likely changes $(\mathrm{n}=80)$

\begin{tabular}{lr}
\hline Themes & $\mathrm{f}$ \\
\hline Target language use & 19 \\
More emphasis on language skills & \\
- Grammar & 4 \\
- Speaking & 4 \\
- Listening & 3 \\
Shorter class time & 10 \\
More learner-centeredness & 6 \\
Adjusting teacher talk to students' level & 5 \\
\hline Total & 51 \\
\hline
\end{tabular}

As the table shows, most of the students would change the target language use, English in other words, $(f=19)$ which actually means to make use of Turkish in teaching. As might be remembered, the ESP practitioner's active use of English in teaching was seen among the strengths of the course; however, the students' response here shows that there were some other students who disliked it, and wanted to change it into Turkish. Student 68 suggested that she/he would change the class into a half Turkish and half English one, as she/he had difficulty in comprehending as it is completely in English. This further shows how heterogeneous the class was, and how diverse the learners' language level and needs were. Moreover, as might be remembered, the scale item regarding the practitioner's use of appropriate teaching methodology revealed moderate satisfaction with a mean value of 3.69, and now the students' demand for less use of English could suggest that what the students mainly meant through dissatisfaction with the practitioner's appropriate use of methodology had something to do with conveying content through English. This could also be the reason why the students thought that the practitioner moderately satisfied them regarding taking their attention to what is being studied $(M=3.43)$ as it was in English which made their 
comprehension harder. Besides, some students wanted more emphasis on language skills, namely grammar $(f=4)$, speaking $(f=4)$, and listening $(f=3)$. For some other students, the class time would better be shorter $(f=10)$. This was mainly because that the weekly classes were all at once, and this made it hard for the students to stay focused. Even though there were breaks in between the class hours, all at once (4 hours) seemed to be a challenge for the students. Besides, some others wanted more learner-centeredness $(f=6)$ through whole-class involvement. They might be right because of the issues stated above. The students, despite few, also wanted the teacher to adjust her talk to their level $(f=5)$ which meant that they had difficulty in clearly understanding what is being talked. For instance S71 stated that "as the course is conducted in English, those whose language level is low do not comprehend the class, and naturally there is no improvement. The results would be positive if what is being said was expressed in Turkish as well." There was even some students who found the coursebook too difficult $(f=1)$.

Last but not the least, the students' suggestions were also elicited regarding likely improvements (see Table 6).

Table 6 Likely improvements $(\mathrm{n}=80)$

\begin{tabular}{lr}
\hline Themes & $\mathrm{f}$ \\
\hline Easing the exams & 16 \\
More homework & 8 \\
More technology & 4 \\
More group work & 3 \\
\hline Total & 31 \\
\hline
\end{tabular}

As the table shows, a great majority of those who wanted to improve something in the course would ease the exams $(f=16)$. This actually makes a lot sense as the practitioner tried to prepare exams having and maintaining validity. Besides, reliability was an important parameter to reveal true and consistent assessments regarding the students' knowledge and performance. This meant that the exams would include assessment of all the skills that were aimed to be developed through the course, and it also had consistent level of difficulty. Thus, these naturally made some students perceive them as hard to do. For instance, what S53 stated can clearly summarize the situation; "what is done in the classes are included in the exams, however, as there are a lot of vocabulary we do not know, we have difficulty in understanding. For this reason, it would be better if they are a little bit easier." This commentary is actually interesting as the student, or perhaps a great majority of them, limit their language comprehension to knowing vocabulary which might also result from the students' lack of knowledge and skills. Thus, they could have developed some sort of compensation strategies in dealing with the language and comprehension. Some others wanted to improve the number and especially the frequency of homework $(f=8)$. A student who asked for more homework, also criticized themselves and stated "we need to be involved in homework more". Thus, as can be seen, even though they asked for more homework, they were also aware that they did not fully involve in the homework assigned. S51 who also asked for more homework was one of those wanted to improve group work studies as they would also contribute to their performance in the exams. Discussions concerning all these issues are provided in the following section. 


\section{DISCUSSION AND CONCLUSION}

As presented in the previous section, the study broadly showed that pedagogical issues such as the practitioner's preparedness for the ESP classes, and subject-matter knowledge, manner to take care of the students' learning and providing them with effective explanations, effective use of materials, and effective presentation of the content are the key issues in the students' high satisfaction of the ESP instruction and ultimately the effectiveness and efficiency of the course. Besides, the educational value and strength of the materials, and their compatibility with the knowledge and skills required for the profession are seen to be highly valued. As for the appropriateness of the materials for the language skills, the students are seen to be concerned mainly about receptive skills which were followed by productive skills and pronunciation as the last matter of concern. As for the course itself, the students were seen to be moderately satisfied with such issues as the class hours, details of which are actually revealed through the open-ended questions and showed that they wanted them to be separately at different times, not at all once. The classroom i.e. its physical size and appropriateness, was another issue that the students found moderately satisfactory. On the other hand, the open-ended questions, seeking to elicit the strengths of the course and the likely changes and improvements that the students would do, are seen to shed light on the reasons lying behind the issues found through the quantitative findings. The open-ended data further showed that the students found the development of their language skills as the basic strength complemented by content-specific instruction supported through the practitioner's active use of English as the medium of instruction. When it comes to the likely changes, the students, or some of them, are seen to complain about dominance of target language use in the classes, and there is no need to say that to some extent this might make sense due to the students' language incompetency, but on the other hand, it is weird as it is an English course which naturally needs to be in English. Furthermore, the exams are seen to be another issue that the students wanted to improve, but this is not for making them become comprehensive rather for making them easier. However, the verbatim data showed that they mainly complained about their difficulty and comprehensiveness which are actually needed for valid and reliable assessment and evaluation. All these issues are of significant value to further understand the students' evaluations of the effectiveness or ineffectiveness of the course.

When all these issues are put together, it is seen that the related body of literature on ESP course evaluation, despite scarce, have similar results. For instance, in his study on the challenges faced by ESP teachers, Saliu (2013) emphasizes inadequate knowledge of a specific content/field as the main issue which is naturally followed by the struggle to design an appropriate syllabus and teaching materials. However, as might be seen through the students' evaluations of the ESP practitioner, the case is almost the opposite in the current study as they found the practitioner prepared for the classes and thought that she had the subject-matter knowledge (see Table 1). Surely, the practitioner's knowledge comes through a heavy background study and preparation for the classes. Without pre-teaching preparation and critical thinking that the practitioner devoted to the content, its presentation, and practice, the results would have been different. Therefore, this clearly shows how significant it is for ESP practitioners to get prepared for the classes they teach as majority of them are not subject-matter experts, rather English language teachers who have the knowledge of teaching methodology, thus can make the input comprehensible for students, but do not have the knowledge of the content itself. The role of the ESP practitioner is clearly summarized by Dudley-Evans (1993: 3), as he stated that "one does not necessarily 
need to have detailed knowledge of the content, but an interest in the discipline and a willingness to find about genre conventions and favored stories". Additionally, the practitioner's preparedness to the classes has a link to the quality of the content-specific instruction that the students are provided with, and which is also reported to be the main contribution of ESP courses (see Papadima-Sophocleous and Hadjiconstantinou 2013).

As for the development of language skills, in line with the results of this study, in their study on the effectiveness of an ESP course for Architecture Iranian students, Aliakbari and Boghayeri (2014) reported that the students regarded reading as more important than writing, speaking, and listening skills. Besides, research has evidence regarding the coursebook as some students are seen to be dissatisfied with it, while there were some others finding it effective as it had tasks worth doing such as vocabulary which overlaps with the findings of the current study (see Aliakbari and Boghayeri 2014; Papadima-Sophocleous and Hadjiconstantinou 2013; Pranckeviciute and Zajankauskaite 2012; Zoghipour 2017). Besides, the students' evaluations upon vocabulary as the first of language skills development is supported by some other studies (see Demirbudak 1992), and deserves attention as it might be an indicator of some kind of compensation strategy use to comprehend written or spoken input especially by the learners of English as foreign language. Thus, this suggests, even without an established knowledge of syntax, students can still benefit from ESP instruction.

Additionally, the students' struggle with the practitioner's use of English as medium of instruction could suggest that they have incompetency in their speaking skills, which was revealed through their responses to the course materials' appropriateness for the development of speaking skills (see Table 2). In such cases, strategy training might be remedy. This is in line with Dhieb-Henia's (2003) study on metacognitive strategy training to equip undergraduate Biology ESP students with the skills to read highly specialized research articles and Pasalic's (2013) study in which students were reported to be not strategic and failed to apply language learning strategies effectively in their progress in ESP. Besides, Dhieb-Henia also emphasized the role of ESP practitioner to be a role-model. Therefore, within the frame of this study, where the students are seen to lack competence in speaking English, and of course any other ESP course whereby ESP practitioners are competent users of target language, role-modelling can act as an implicit strategy to raise students' awareness on the active and effective use of target language. In this sense, an ESP practitioner who can successfully convey the content-specific instruction through English is ultimately an advantage in ESP courses, especially for those taking place in contexts whereby English is foreign language and students have little or even no opportunity to be exposed to English out of the class. However, students', despite not all, bizarre attitude towards the use of English as the medium of instruction further calls for the need to raise their awareness regarding the role and contributions of English in the class.

As for the students' concerns about making the exams easier, it is necessary to mention that the practitioner was aware of such issues as test content, its method (direct or indirect), and its validation (see Alderson, 1988) as the exams needed to measure knowledge and skills related to the content area they needed to acquire and develop at that time, over the course of the ESP course, and need to use in their future employment. For instance, as generally acknowledged, Banking and Finance is a field in which knowledge of English is of vital importance as it has a close link to the international finance arena. Therefore, the students were taught to read and interpret financial graphics whereby they needed to describe finance or currency trends. They were also assessed on these skills in the exams. 
However, possibly due to inadequate knowledge of English in general, the content, assessment method, and its validity acted as issues making the students perceive the exams difficult.

Furthermore, as Strevens (1988) suggested, the emergence of ESP has also produced problems for its practitioners, learners, methodology and materials, and assessment and evaluation, and this is what complements some of the findings revealed through the current study. For instance, although some students were seen to favor the practitioner's active use of English as medium of instruction, some found it discouraging, as they thought that it debilitated their likeliness to be involved in the class. Besides, while majority were seen to regard the coursebook as appropriate (see Table 2), there were still some others, despite few, who found it as an issue of change as they found it difficult. Moreover, despite listening skills were found as one of the two skills which were thought to be appropriately met by the course materials (see Table 2), there were still some others who thought that there could be more emphasis on it (see Table 4). Last, but not the least, some students thought that exams should have been easier (see Table 5). Thus, as can clearly be seen, no matter how effective it was, it was not still free of problems, and as Strevens (1998) suggested any problem faced in ESP courses can be solved. However, it is not an easy task. There needs to be better ESP practitioners who are supported through constant and quality training to acquire the knowledge and skills which are needed to develop insights for how to define appropriate methodology, to select and design appropriate materials, and also to prepare and improve appropriate means for the assessment and evaluation of students.

Moreover, this shows that for the effectiveness and efficiency of an ESP course, there are different parameters, and ESP practitioners are one of them. However, this cannot guarantee anything. No matter how an ESP teacher is competent in teaching ESP courses, should learners be motivated and active to make sense of the ESP instruction. In this regard, as Hutchinson (1988) stated, ESP is a process whereby learners need to be "active participants in the learning process" (p. 72) through active thinking and taking the initiative to make decisions for their own learning. Thus, it is not only how much ESP students are involved in the development of their skills, but also how much they actively process ESP knowledge, and think on it to make the most of it. In this sense, such demands regarding the likely improvements and changes as more learner-centeredness, adjustment of teacher talk to the students' level, or more group work might easily be overcome if students are active parties and decision makers in ESP teaching and learning process. This also has a strong link to the truth that ESP is a response to the specific needs of learners. However, there might be challenges along the way to meet the needs if learners are not homogenously grouped. Thus, there might still be criticisms as revealed in Demirbulak's (1992) study and also in the current study as the students found some issues as class time and technology integration which they thought to need change and improvement.

Consequently, despite having its own boundaries, and context, the effectiveness and efficiency of ESP courses is not a mono-dimensional issue. As can clearly be understood what has been reported and discussed so far, there are a variety of parameters including competencies of ESP practitioners to design and implement a course matching learners' needs and expectations as much as possible even when there is no needs assessment. It is not enough on its own as ESP practitioners also need to be prepared for classes which means lots of preparation to perform effectively in the class. Besides, making use of appropriate materials is also vital as students may have different perceptions regarding the skills they need. Moreover, ESP practitioners also need to be aware that students might not 
be satisfied even though they need them. For this reason, if possible, their reactions regarding ESP instruction should be elicited at different intervals particularly to eliminate the likely challenges along the way resulting in low performance and motivation. However, all these issues are unfortunately not piece of cake things. They require considerable thought and work, and this is where it calls for administrational support to ESP practitioners who are mostly left alone alongside the process and are expected to teach ESP. Last, but not the least, students' awareness regarding their roles and the significance of their active involvement in ESP course process is another important factor.

\section{REFERENCES}

Alderson, J. Charles, "Testing and its administration in ESP". In ESP in the classroom: Practice and Evaluation Edited by D. Chamberlain and R. J. Baumgardner, 87-97 Hong Kong: Modern English Publications and The British Council, 1988.

Aliakbari, Mohammad and Boghayeri, Mahnaz. "A needs analysis approach to ESP design in Iranian context”. Procedia-Social and Behavioral Sciences, 98, (2014): 175-181.

Demirbulak, Dilara. "Learners' perceptions in the evaluation of an ESP course". Unpublished MA Thesis Bilkent University, 1992.

Dhieb-Henia, Nebila. "Evaluating the effectiveness of metacognitive strategy training for reading research articles in an ESP context". English for Specific Purposes, 22, (2003): 387-417

Dörnyei, Zoltan. Research Methods in Applied Linguistics. Oxford: Oxford University Press, 2007.

Dudley-Evans, Tony. "Subject specificity in ESP: How much does the teacher need to know of the subject?" la revue du GERAS AsP 1 (1993) Online available at http://journals.openedition.org/asp/4354

Dudley-Evans, Tony and St. John, Maggie. Developments in English for specific purposes. A multi-disciplinary approach. Cambridge: Cambridge University Press, 1998.

Duff, Patricia. Case study research in Applied Linguistics. New York: Lawrence Erlbaum Associates, 2008.

Hatam, Amir Hussein and Shafiei, Shilan. "The evaluation of the effectiveness of ESP courses in enhancing technical translation proficiency: A case study of the ESP course for mechanical engineering students". English Language Teaching, 5 no.5 (2012): 6878. URL: http://dx.doi.org/10.5539/elt.v5n5p68

Hutchinson, Tom (1988). "Making materials work in the ESP classroom". In ESP in the classroom: Practice and Evaluation Edited by D. Chamberlain and R. J. Baumgardner, 71-75 Hong Kong: Modern English Publications and The British Council, 1988.

Hutchinson, Tom and Waters, Alan. English for specific purposes. A learning-centered approach. Cambridge: Cambridge University Press, 1987.

Krippendorff, Klaus. Content analysis. An introduction to its methodology. Thousand Oaks, California. SAGE Publications, 2004.

Ilin, Gülden, Kutlu, Özge, and Kutluay, Abdurrahman. "An action research: using videos to teach grammar in an ESP class". Procedia-Social and Behavioral Sciences, 70, (2013): 272-281.

Lesiak-Bielawska, Elzbieta. D. "English for instrumentalists: Designing and evaluating an ESP course". English for Specific Purposes World, 43, no. 15 (2014):1-32. 
Morgan, Philip. "The course improvement flowchart: A description of a tool and processes for the evaluation of university teaching". Journal of University Teaching \& Learning Practice, 5, no.2, (2008): 1-16.

Nunan, David and Bailey, Kathleen. M. Exploring second language classroom research. A comprehensive guide. Canada: HEINLE CENGAGE Learning, 2009.

Paltridge, Brian and Starfield, Sue. The handbook of English for specific purposes. $\left(1^{\text {st }}\right.$ ed.). West Sussex: Wiley-Blackwell Publishing, 2013.

Papadima-Sophocleous, Salomi., and Hadjiconstantinou, Stravroulla. "Students' reflections on the effectiveness of their ESAP courses: A multidisciplinary evaluation at tertiary level." English for Specific Purposes World, 38, no.14, (2013): 1-27.

Pasalic, Magda. Language learning strategies and progress in EFL of students of Economics and Business. ESP Today Journal of English for Specific Purposes at Tertiary Level, 1, no.1, (2013): 127-138.

Pranckeviciute, Vilma and Zajankauskaite, Zita. Adjusting an ESP course to students' needs in tertiary education: a case study. Studies about Languages, 21, (2012): 115-122.

Saliu, Basri. Challenges for learners/teachers in the ESP course for legal studies. SEEU Review, 9, no.1, (2013):1-8.

Strevens, Peter. "The learner and teacher of ESP". In ESP in the classroom: Practice and Evaluation Edited by D. Chamberlain and R. J. Baumgardner, 39-44 Hong Kong: Modern English Publications and The British Council, 1988.

$\mathrm{Su}$, Shao-Wen. "Designing and delivering an English for hospitality syllabus: A Taiwanese case study." RELC-Regional Language Center Journal, 40, no.3, (2009): 280-313.

Tsou, Wenli \& Chen, Fay. ESP program evaluation framework: Description and application to a Taiwanese university ESP program. English for Specific Purposes, 33, (2014): 39-53.

Zoghipour, Mahsa. “A critical evaluation of the Iranian Universities' English for Specific Academic Purposes (ESAP) courses: The case of the ESAP courses for engineering students of the Azerbaijan Shahid Madani University". The Journal of Teaching English for Specific and Academic Purposes, 5, no.4 (2017): 647-660. 